\title{
Improvement of colitis by Lactobacillus plantarum LS/07 and inulin
}

\author{
Emília Hijová, Alena Šoltésová, Izabela Bertková, Jana Štofilová, Ladislav Strojný, \\ Alojz Bomba
}

Institute of Experimental Medicine, Medical Faculty, University of P. J. Šafárik, Košice, Slovak Republic

Received May 24, 2016

Accepted December 19, 2017

\begin{abstract}
The objective of this study was to investigate the effect of the probiotic strain Lactobacillus plantarum LS/07 and prebiotic inulin on the activity of $\beta$-glucuronidase, transcription nuclear factor kappa B (NFאB), myeloperoxidase (MPO), cytokine levels (IL-6, IL-8, IL-13), and counts of coliforms and lactobacilli in rats with dextran sulphate sodium (DSS) induced acute colitis. Sprague-Dawley rats were divided into groups: control (C), acute colitis (AC), prebiotic (Pre), and probiotic (Pro). Dextran sulphate sodium induced inflammatory process in the colonic tissue, increased the activity of $\beta$-glucuronidase $(P<0.05)$, increased counts of coliforms, decreased lactobacilli counts $(P<0.05)$, and activated production of the measured indicators NFKB, MPO, IL-6, IL-8, except of IL-13. Diet supplemented with L. plantarum and inulin alleviated DSS induced inflammatory process by inhibiting production of IL-6, IL-8, activities of NFKB and MPO, and by stimulation of IL-13. These results indicate that the dietary intake of Lactobacillus plantarum LS/07 and inulin suppressed the expression of markers playing an important role in the inflammatory process, which predisposes their use in prevention or treatment of acute colitis.
\end{abstract}

Inflammatory bowel diseases, rats, inflammation, prebiotics, probiotics

Ulcerative colitis (UC) as a nosological unit within inflammatory bowel diseases (IBD) is a chronic, nonspecific relapsing disease characterised by diffuse mucosal inflammation limited to the colon but it can also affect other areas of the digestive tract in humans. Similar disorders are also present in several animal species (Kalck 2009; Cerquetella et al. 2010).

The course of UC is characterized by an impact frequency of unpredictable occurrence of relapse (acute inflammation) and remission (inflammation in decline), but the aetiology of UC has not yet been understood. In genetically susceptible individuals, an abnormal communication between the intestinal microbiota and the mucosal immune system forms the basis of the defect, which is accompanied by mucosal inflammatory lesions of the gastrointestinal tract. Studies on animal models of colitis has led to the hypothesis that genetic factors and enteric bacteria can play a pivotal role in the pathogenesis of these disorders, owing to the abnormal intestinal response to commensal microflora (Burgener et al. 2008; Liu et al. 2009). Long-standing UC has a higher risk of developing colitisassociated cancer (CAC) approximately 8-10 years after the initial diagnosis when compared to the general population (Jones et al. 2014). In addition to genomic instability that underlies the process of tumorigenesis, continuous inflammation in the intestine seems to be a key factor in CAC development since chronic inflammation is associated with an overexpression of proinflammatory cytokines, chemokines, growth factors as well as their receptors, and reactive oxygen species (Kanneganti et al. 2011; Hijová et al. 2014). Ulcerative colitis is a serious medical and socio-economic problem with an increasing incidence and prevalence. The decreased quality of life associated with it is the reason for seeking new possibilities for its prevention and treatment.

In general, the first approach with UC usually involves dietary modification of bacterial

Address for correspondence:

MVDr. Emília Hijová, $\mathrm{PhD}$

Institute of Experimental Medicine

Medical Faculty, University of P. J. Šafárik

SNP 1, 04011 Košice, Slovak Republic
Phone +421552343463

E-mail address: emilia.hijova@upjs.sk

http://actavet.vfu.cz/ 
flora, the use of probiotics and prebiotics may attenuate the inflammatory process and prevent relapses and maintenance of remission in ulcerative colitis.

The aim of the presented study was to obtain information regarding the effects of the probiotic Lactobacillus plantarum LS/07 and of prebiotic inulin on the activity of $\beta$-glucuronidase and counts of coliform and lactobacilli in fresh caecal digesta, cytokine levels (IL-6, IL-8, IL-13), transcription nuclear factor kappa B (NFKB) and myeloperoxidase (MPO) activities in the colon tissue and blood samples of rats with dextran sulphate sodium (DSS) induced acute colitis.

\section{Materials and Methods}

Male Sprague-Dawley rats $(\mathrm{n}=32,7$ weeks old, 220-290 g body weight) were placed in the Laboratory of Research Bio-models of the Faculty of Medicine, University of P. J. Šafárik, Slovak Republic (SK PC 4013). The room was maintained at $21 \pm 1{ }^{\circ} \mathrm{C}$ with $50-60 \%$ humidity and 12 -h light/dark cycle. All animal experiments were conducted in accordance with the principles outlined in Law No. 377/2012 and No. 436/2012 of the Slovak Republic for the Care and Use of Laboratory Animals, and were approved by the Ethics Committee of the University of P.J. Šafárik, Faculty of Medicine and State Veterinary and Food Administration of the Slovak Republic (Ro-1136/14-221).

The rats were randomly assigned to four groups: control group (C) received the conventional MP-OŠ-06 feed (Snina, Slovak Republic) at an interval of 14 days; the acute colitis group (AC) received the conventional feed without DSS at an interval of 7 days followed by 7 days of feed with DSS; the prebiotic group (Pre) received the conventional feed supplemented with prebiotic inulin (BeneoSynergy 1, ORAFTI, Tienen, Belgium) at a dose of $80 \mathrm{~g} / \mathrm{kg}$ feed without DSS at an interval of 7 days, followed by 7 days of the same feed with DSS; and the probiotic group (Pro) received the conventional feed with the probiotic Lactobacillus plantarum LS/07 given in pasteurized milk containing $0.5 \%$ fat at a daily dose $1.5 \times 10^{9} \mathrm{CFU} / 1 \mathrm{ml}$, without DSS at an interval of 7 days, and then for 7 days with DSS. Colitis was induced using DSS (molecular weight 40000 , TdB Consulting AB, Uppsala, Sweden) added to drinking water at a final concentration of $5 \%(\mathrm{wt} / \mathrm{vol})$ for 7 days. Controls were all time-matched and consisted of rats receiving normal drinking water only. The DSS solution was replenished daily and mean DSS consumption was noted per cage at the end of the 7-day treatment. All animals had free access to water and feed. Animal weights and clinical monitoring of the health status were recorded daily. After 14 days of consuming the experimental diets, the animals were euthanized under anaesthesia Zoletil (Virbac S.A., France) administered at a dose of $50 \mathrm{mg} / \mathrm{kg}$ body weight with xylazine (Riemser, Germany) at a dose of $15 \mathrm{mg} / \mathrm{kg}$ body weight, intramuscularly). Blood samples were drawn by cardiac puncture to measure selected indices. Caecal and tissue samples from the colon were recovered for biochemical and immunological analyses.

The disease activity index (DAI) is the combined score of animal weight loss, stool consistency and bleeding in stool. Stool probes were tested to evaluate rectal bleeding using HemoFEC test (Roche Diagnostics, Slovak Republic). All indices were assessed on a scale from 0 to 3 or 4 , the maximum score was 10 . These indices were each assigned a score and utilized to calculate an average daily disease activity index score for each rat as previously described (Vasina et al. 2010).

The probiotic strain of Lactobacillus plantarum LS/07 was isolated from rectal human swabs reported by Strojný et al. (2011). The strain was cultured in MRS broth (Merck, Germany) prepared as night cultures at $37^{\circ} \mathrm{C}$ aerobically and provided at a dose of $3 \times 10^{9} \mathrm{CFU}$ of strain $/ 1 \mathrm{ml}$. Then $0.5 \mathrm{ml}$ of lactobacilli strains mixed with $9 \mathrm{ml}$ of pasteurized milk $\left(20-22{ }^{\circ} \mathrm{C}\right)$ was filled into bottles and administered individually every day. Each rat received approximately $1.5 \times 10^{9} \mathrm{CFU}$ lactobacilli via the oral route. The Rogosa agar plates for lactobacilli culturing were maintained under anaerobic conditions (BD GasPak, Becton, Dickinson and Company, USA) and incubated at $37^{\circ} \mathrm{C}$ for $48 \mathrm{~h}$. McConkey agar plates used for coliform culturing were incubated aerobically at $37^{\circ} \mathrm{C}$ for $16-18 \mathrm{~h}$. The numbers of colony forming units (CFU) are expressed as $\log _{10} \mathrm{CFU}$ per gram of faeces.

The activity of $\beta$-glucuronidase ( $\beta$-GLUCUR) enzyme was measured in fresh caecal digesta with a method previously described by Juskiewicz et al. (2002). A measurement unit of enzymatic activity is expressed as $\mu \mathrm{mol}$ of $p$-nitrophenol per min per gram digesta.

Samples of blood were to clot for $2 \mathrm{~h}$ at room temperature before centrifugation for $15 \mathrm{~min}$ at $1000 \times g$, removed serum samples were stored at $-20^{\circ} \mathrm{C}$. Tissue samples from the entire colon were rinsed in ice-cold PBS (pH 7.0-7.2) to thoroughly remove excess blood, then they were cut longitudinally and homogenized in PBS with a homogenizer on ice (Disperser T10 Basic Ultra Turrax, Germany), and stored overnight at $-20^{\circ} \mathrm{C}$. Two freeze-thaw cycles were performed to break the cell membranes. Next, the homogenates were centrifuged for 5 min at $5000 \times g$ at $4{ }^{\circ} \mathrm{C}$; supernatants were removed and stored at $-20{ }^{\circ} \mathrm{C}$. All endpoints were measured by ELISA method as follows: NFאB in tissue by USCN Life Science, Inc., USA; IL-6 in blood and tissue by eBioscience, IL-8 and IL-13 in tissue by Cusabio (Biotech Co., China), and MPO in tissue and blood by BlueGene (Biotech Co., China). The final values of each indicator were measured on the Synergy H4 multiplate reader (BioTek Instruments, Inc. USA). 
The data were expressed as mean $\pm \mathrm{SD}$. One-way analysis of variance and Tukey test (MINITAB for Windows 11.21) was used to evaluate significance of differences between the control and experimental groups. Differences were considered significant at $P<0.05$.

\section{Results}

The final mean body weight of the animals compared to the initial weight was increased in group C by $30.92 \%$, in group AC by $9.90 \%$, in group Pre by $14.28 \%$, and in group Pro by $21.74 \%$. The average value of all daily disease activity index score showed that the maximum DAI score $=6.50$ was in the AC group. A decrease of the DAI score was observed after application of prebiotic inulin $=4.13$ and probiotic Lactobacillus plantarum LS/07 $=3.50$. Changes in the monitored indices correspond to the changes in weight as well as the results of the DAI score. Within a short experimental period, preventive dietary supplementation with prebiotic inulin and Lactobacillus plantarum LS/07 positively decreased the activity of $\beta$-glucuronidase which is believed to be a biomarker of increased risk of neoplasm. The activity of $\beta$-glucuronidase was significantly increased $(P<0.05)$ in group AC. Lactobacillus plantarum LS/07 and inulin positively reduced the activity of $\beta$-glucuronidase $(P<0.05)$, (Table 1$)$. Acute colitis elevated (non-significantly) the number of coliforms and significantly $(P<0.05)$ decreased the number of lactobacilli in group AC compared to the control group (Table 1). Table 2 shows changes in NFкB and MPO activities in serum (s) and colon tissue $(\mathrm{t})$ in the control group, the acute colitis group, and in the groups treated with inulin and probiotic. Serum and tissue cytokine levels of IL-6, IL-8 and IL-13 in C, AC, Pre and Pro groups are shown in Table 3.

Table 1 . The effect of administration of inulin and L. plantarum LS/07 on the $\beta$-glucuronidase activity and total counts of lactobacilli and coliform caecal content in rats.

\begin{tabular}{lcccc}
\hline Indicator & $\begin{array}{c}\mathrm{C} \\
(\mathrm{n}=8)\end{array}$ & $\begin{array}{c}\mathrm{AC} \\
(\mathrm{n}=8)\end{array}$ & $\begin{array}{c}\text { Pre } \\
(\mathrm{n}=8)\end{array}$ & $\begin{array}{c}\text { Pro } \\
(\mathrm{n}=8)\end{array}$ \\
\hline$\beta$-GLUCUR $\mu \mathrm{mol} / \mathrm{min} / \mathrm{g}$ & $0.14 \pm 0.02^{\mathrm{b}}$ & $0.54 \pm 0.05^{\mathrm{a}}$ & $0.49 \pm 0.18^{\mathrm{a}}$ & $0.39 \pm 0.18^{\mathrm{a}}$ \\
Lactobacilli $\log _{10} \mathrm{CFU} / \mathrm{g}$ & $7.78 \pm 0.17^{\mathrm{a}}$ & $7.15 \pm 0.90^{\mathrm{b}}$ & $7.31 \pm 0.45^{\mathrm{a}}$ & $7.40 \pm 0.44^{\mathrm{a}}$ \\
Coliforms $\log _{10} \mathrm{CFU} / \mathrm{g}$ & $5.18 \pm 0.56$ & $5.74 \pm 1.03$ & $5.51 \pm 0.77$ & $5.19 \pm 0.57$ \\
\hline
\end{tabular}

C - control group, AC - acute colitis group, Pre - prebiotic group, Pro - probiotic group. The data are presented as mean \pm standard deviation (S.D.), ${ }^{\text {a,b }}$ - values in a row sharing different superscipts are significantly different $(P<0.05)$

Table 2. The effect of administration of inulin and L. plantarum LS/07 on NF $\kappa$ B and MPO activities in serum (s) and tissue $(\mathrm{t})$ in rats.

\begin{tabular}{lcccc}
\hline Indicator & $\begin{array}{c}\mathrm{C} \\
(\mathrm{n}=8)\end{array}$ & $\begin{array}{c}\mathrm{AC} \\
(\mathrm{n}=8)\end{array}$ & $\begin{array}{c}\text { Pre } \\
(\mathrm{n}=8)\end{array}$ & $\begin{array}{c}\text { Pro } \\
(\mathrm{n}=8)\end{array}$ \\
\hline NFкB (t) $\mathrm{ng} / \mathrm{ml}$ & $41.73 \pm 7.41^{\mathrm{b}}$ & $60.21 \pm 10.31^{\mathrm{a}}$ & $11.65 \pm 1.32^{\mathrm{c}}$ & $50.52 \pm 17.56^{\mathrm{a}, \mathrm{b}}$ \\
MPO (s) $\mathrm{pg} / \mathrm{ml}$ & $53.38 \pm 30.53^{\mathrm{b}}$ & $98.78 \pm 18.26^{\mathrm{a}}$ & $88.35 \pm 10.49^{\mathrm{a}}$ & $69.94 \pm 32.95^{\mathrm{a}, \mathrm{b}}$ \\
MPO (t) $\mathrm{pg} / \mathrm{ml}$ & $362.53 \pm 71.55^{\mathrm{a}, \mathrm{b}}$ & $424.12 \pm 73.46^{\mathrm{a}}$ & $296.96 \pm 63.78^{\mathrm{b}}$ & $346.04 \pm 92.13^{\mathrm{a}, \mathrm{b}}$ \\
\hline
\end{tabular}

C - control group, AC - acute colitis group, Pre - prebiotic group, Pro - probiotic group. The data are presented as mean \pm standard deviation (S.D.), ${ }^{\mathrm{a}, \mathrm{b}, \mathrm{c}}-$ values in a row sharing different superscripts are significantly different $(P<0.05)$ 
Table 3. The effect of administration of inulin and L. plantarum LS/07 on cytokine levels of IL-6, IL-8 and IL-13 in serum ( $\mathrm{s}$ ) and tissue $(\mathrm{t})$ in rats.

\begin{tabular}{lcccc}
\hline Indicator & $\begin{array}{c}\mathrm{C} \\
(\mathrm{n}=8)\end{array}$ & $\begin{array}{c}\mathrm{AC} \\
(\mathrm{n}=8)\end{array}$ & $\begin{array}{c}\text { Pre } \\
(\mathrm{n}=8)\end{array}$ & $\begin{array}{c}\text { Pro } \\
(\mathrm{n}=8)\end{array}$ \\
\hline IL-6 s pg/ml & $49.31 \pm 15.83^{\mathrm{a}, \mathrm{b}}$ & $61.89 \pm 15.33^{\mathrm{a}}$ & $45.83 \pm 9.99^{\mathrm{a}, \mathrm{b}}$ & $43.00 \pm 6.09^{\mathrm{b}}$ \\
IL-6 t pg/ml & $47.00 \pm 8.53^{\mathrm{b}}$ & $62.65 \pm 12.19^{\mathrm{a}}$ & $48.77 \pm 5.31^{\mathrm{a}, \mathrm{b}}$ & $41.27^{\mathrm{a}} \pm 14.88^{\mathrm{b}}$ \\
IL-8 t pg/ml & $37.78 \pm 7.42^{\mathrm{c}}$ & $50.12 \pm 7.32^{\mathrm{a}}$ & $47.67 \pm 8.49^{\mathrm{a}, \mathrm{b}}$ & $39.34 \pm 5.39^{\mathrm{b}, \mathrm{c}}$ \\
IL-13 t pg/ml & $62.81 \pm 5.99^{\mathrm{a}}$ & $47.87 \pm 6.91^{\mathrm{b}}$ & $57.93 \pm 11.26^{\mathrm{a}, \mathrm{b}}$ & $53.20 \pm 14.52^{\mathrm{a}, \mathrm{b}}$ \\
\hline
\end{tabular}

C - control group, AC - acute colitis group, Pre - prebiotic group, Pro - probiotic group. The data are presented as mean \pm standard deviation (S.D.), ${ }^{\mathrm{a}, \mathrm{b}, \mathrm{c}}$ - values in a row sharing different superscripts are significantly different $(P<0.05)$

\section{Discussion}

Experimental and clinical data so far support the hypothesis that prebiotics such as inulin and oligofructose and probiotic strains offer the opportunity to prevent or mitigate intestinal inflammatory lesions, modulate the intestinal microbiota and the host immune system in gastrointestinal disorders, and provide an alternative or adjuvant approach to conventional therapy (Looijer van Langen and Dieleman 2009; Verna and Lucak 2010; Mack 2011). For UC, interactions are expected between genetic, immunologic, microbial and environmental factors, while the exact aetiology and pathogenesis are still unclear. Chronic inflammation is known to lead to derangement in the signalling processes and to a local microenvironment described as lying somewhere between pre-cancerous stromal cells and cancer cells, even as the details of the steps in the transformation to a cancer cell are not completely understood (Nathan and Ding 2011). Signalling pathways triggered by $\mathrm{NF} \kappa \mathrm{B}$ play a key role in the colonic inflammation development. The NF $\kappa \mathrm{B}$ regulates the expression of various cytokines and modulates the inflammatory processes characteristic of IBD (Atreya et al. 2008; Luckschander et al. 2010). The NFkB controls apoptosis, cell-cycle progression, cell proliferation, and differentiation. Normally functioning NFKB is essential for the maintenance of epithelial cell homeostasis in the gut. Translocation of activated NFKB into the nucleus induces the expression of genes for cytokines such as TNF $\alpha$ and IL-6, and chemokines, all of which contribute to the development of inflammationrelated tissue damage.

In our study, the activity of NFKB in colon tissue samples was markedly increased in group $\mathrm{AC}(P<0.05)$ which may provide a sensitive means of assessing the state of activation of the mucosal immune response. Inulin treatment suppressed the activity of critical transcription factor in mucosa cells $(P<0.05)$. The application of Lactobacillus

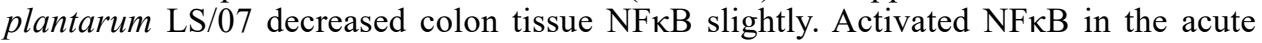
colitis group significantly activated serum and colon tissue levels of pro-inflammatory cytokine (IL-6 and IL-8) compared to the control group. Inulin diet intervention in group Pre significantly downregulated the synthesis of proinflammatory cytokines IL-6 $(P<0.05)$ in serum and colon tissue and IL-8 $(P<0.05)$ in tissue compared to group AC. Lactobacillus plantarum LS/07 significantly downregulated the synthesis of IL-6 and IL-8 $(P<0.05)$ compared to group AC. Inulin and Lactobacillus plantarum LS/07 stimulated IL-13 production thus demonstrating their anti-inflammatory activity and immune enhancing effect.

Evaluating the MPO activity is crucial for understanding its effects in inflammation, since it is the most abundant proinflammatory enzyme stored in the azurophilic granules of neutrophilic granulocytes. Neutrophil accumulation in the inflamed intestinal mucosa 
is a prominent feature in ulcerative colitis. Extracellular MPO activity gives an estimate of oxidative stress in inflammatory diseases, whereas intracellular MPO activity correlates well with the tissue neutrophil content (Pulli et al. 2013). The determination of MPO can be used as one of the non-invasive markers of disease and prediction of relapse, and is also considered as an inflammatory damage marker. Increased activities of MPO were found in serum and colon tissue homogenate of rats. Its activity was significantly suppressed by administration of prebiotics and probiotics. The release of MPO correlated with an enhanced local release of the neutrophil activating interleukine-8 (Massodi et al. 2011).

Within the short experimental period, the preventive dietary supplementation with inulin and probiotic positively modified the values of observed microorganisms and activity of $\beta$-glucuronidase. Presented experimental data demonstrate the ability of the prebiotic inulin and probiotic Lactobacillus plantarum LS/07 to intervene and affect the pathophysiological process of development of acute colitis. The exact aetiology and pathogenesis of ulcerative colitis is not yet known, but the use of prebiotics and probiotics appear to be a suitable form of preventing acute colitis in human and veterinary medicine.

\section{Acknowledgement}

This work was supported by the Research Agency Slovak Republic for the Structural Funds of the EU under project ITMS 26220120058, ITMS 26220220104 and grant 4/GSD/2012.

\section{References}

Atreya I, Atreya R, Neurath MF 2008: NF-kappaB in inflammatory bowel disease. J Intern Med 263: 591-596 Burgener IA, König A, Allenspach K, Sauter SN, Boisclair J, Doherr MG, Jungi TW 2008: Upregulation of toll-like receptors in chronic enteropathies in dogs. J Vet Intern Med 22: 553-560

Cerquetella M, Spaterna A, Laus F, Tesci B, Rossi G, Antonelli E, Villanacci V, Bassotti G 2010: Inflammatory bowel diseases in the dog: Differences and similarities with humans. World J Gastroenterol 16: 1050-1056

Hijová E, Szabadosova V, Štofilová J, Salaj R, Bomba A 2014: Inulin diet intervention on chemopreventive and inflammatory markers in tumorigenesis of colorectal cancer. Acta Veterinaria-Beograd 64: 519-525

Jones R, Scobey M, Cheng J 2014: The risk of colon cancer in inflammatory bowel disease. J Gastroin Dig Sys 4: 1-3

Juskiewicz J, Zdunczyk Z, Wroblewska M, Oszmianski J, Hernandez T 2002: The responce of rats to feeding with diets containing grapefruit flavonoid extract. Food Res Int 35: 201-205

Kalck KA 2009: Inflammatory bowel disease in horses. Vet Clin North Am Equine Pract 25: 303-315

Kanneganti M, Kenudson MM, Mizoguchi E 2011: Animal models of colitis-associated carcinogenesis. J Biomed Biotechnol 2011: ID 342637, 1-23

Liu X, Mei Q, Xu J, Hu J 2009: Balsalazine decreases intestinal mucosal permeability of dextran sulfate sodium-induced colitis in mice. Acta Pharmacol Sin 30: $987-993$

Looijer-van Langen MAC, Dieleman LA 2009. Prebiotic in chronic intestinal inflammation. Inflamm Bowel Dis 15: 454-462

Luckschander N, Hall JA, Gaschen F, Forster U, Wenzlow N, Hermann P, Allenspach K, Dobbelaere D, Burgener IA, Welle M 2010: Activation of nuclear factor kappa B in dogs with chronic enteropathies. Vet Immunol Immunopathol 133: 228-236

Mack DR 2011: Probiotics in inflammatory bowel diseases and associated conditions. Nutrients 3: 245-264

Massodi I, Tijjani BM, Wani H, Hassan NS, Khan AB, Hussain S 2011: Biomarkers in the management of ulcerative colitis: a brief review. German Medical Science 9: 1-7

Nathan C, Ding A 2011: Nonresolving inflammation. Cell 140: 871-882

Pulli B, Ali M, Forghani R, Schob S, Hsieh KLC, Wojtkiewicz G, Linnoila JJ, Chen JW 2013: Measuring myeloperoxidase activity in biological samples. PLOS One 8: 1-10

Strojný L, Bomba A, Hijová E, Chmelárová A, Mojžišová G, Bertková I, Koprovičová J, Pomfy M, Strompfová V, Molokáčová M 2011: Effects of probiotic in combination with prebiotics on intestinal lactobacilli and coliforms and activities of bacterial enzymes in 1,2-dimethylhydrazine exposed rats. Czech J Anim Sci 56: 99-106

Vasina V, Brocolli M, Ursino MG, Canistro D, Valgimigli L, Soleti A, Paolini M, DePonti F 2010: Non-peptidyl low molecular weight radical scavenger IAC attenuates DSS-induced colitis in rats. World J Gastroenterol 16: $3642-3650$ 
Verna EC, Lucak S 2010: Use of probiotics in gastrointestinal disorders: what to recommend? Therap Adv Gastroenterol 3: 307-319 